\title{
Retraction Note to: Inhaled corticosteroids and long-acting beta-agonists in adult asthma: a winning combination in all?
}

\author{
Dirkje S. Postma • Huib A. M. Kerstjens • \\ Nick H. T. ten Hacken
}

Published online: 8 May 2009

(C) Springer-Verlag 2009

Erratum to: Naunyn-Schmied Arch Pharmacol (2008) 378:203-215

DOI 10.1007/s00210-008-0302-y

It has come to the attention of the journal, that a review article published last year (Postma et al. 2008) contains several passages which are identical to text published by other authors (Giembycz et al. 2008) without giving reference to the original source of these text blocks. The journal has come to the conclusion that this constitutes plagiarism and hence has decided to retract the paper.

\section{References}

Giembycz MA, Kaur M, Leigh R, Newton R (2008) A holy grail of asthma management: toward understanding how long-acting $\beta_{2^{-}}$ adrenoceptor agonists enhance the clinical efficacy of inhaled corticosteroids. Br J Pharmacol 153:1090-1104

Postma DS, Kerstjens HAM, ten Hacken NHT (2008) Inhaled corticosteroids and long-acting beta-agonists in adult asthma: a winning combination in all? Naunyn-Schmiedeberg's Arch Pharmacol 378:203-215

The online version of the original article can be found at http://dx.doi. org/10.1007/s00210-008-0302-y. 